sented sequence or allele frequency data showing that repeat lengths tend to be longer in the species from which markers have been cloned than in a related species (Table 1). Together with our two comparisons, this reveals a highly significant difference between repeat lengths in the two categories of species $\left(\chi^{2}=40.21\right.$, d.f. $=12, P<$ 0.001 , Fisher's combined probability). Second, there are several examples, from various taxa, of sets of polymorphic microsatellites which reveal considerably lower degrees of genetic variability in inter- than in intraspecific amplification ${ }^{4}$. Because of the positive relationship between repeat length and polymorphism ${ }^{3}$, this suggests that homologous loci in a related species generally harbour shorter repeats than in the species from which markers were cloned. Third, our prediction of shorter repeats in homologues could logically be extended to predict that the difference in repeat length will increase with increasing genetic distance. Given the positive relationship between repeat length and polymorphism ${ }^{3}$, there should thus be a negative relationship between distance and degree of Hans Ellegren ${ }^{1}$ polymorphism. Using data from Craig R. Primmer ${ }^{1}$ our recent survey of the ability of Ben C. Sheldon ${ }^{1,2}$ bird microsatellites to uncover polymorphism throughout the class Aves $^{5}$ we find the predicted negative relationship between distance and variability $(\mathrm{r}=1.0, n=7$, $z=2.45, P=0.01$; Fig. 1). Limited polymorphism is retained above distances corresponding to $30 \mathrm{MYR}$ of divergence.

In short, although we do not exclude the possibility that there indeed is a difference in microsatellite mutation rate between species, such as primates, we argue that this conclusion cannot be drawn from comparisons of repeat lengths at loci which have been chosen because of their length in just one species. Critical tests need to based on the reciprocal use of markers developed from more than one species or on the random choice of loci with respect to their repeat lengths.

\section{Acknowledgment}

We thank A. Read for helpful discussions. F. Sheldon is gratefully acknowledged for providing Hirundinidae samples.
${ }^{3}$ Department of Animal Breeding and Genetics, Swedish University of Agricultural Sciences, Biomedical Centre, Box 597, S-751 24 Uppsala, Sweden

${ }^{2}$ Department of Zoology, Section of Animal Ecology, Uppsala University, Villavägen 9, S-752 36 Uppsala, Sweden

Correspondence should be addressed to H.E.

1. Rubinsztein et al. Nature Genet. 10, 337-343
(1995).
2. Beckman, J.S. \& Weber, J.L. Genomics 12,
$627-631$ (1992).
3. Weber, J.L. Genomics 7, 524-530 (1990).
4. Moore, S.S. et al. Mamm. Genome 5, 84-90
(1994).
5. Primmer, C.R., Møller, A.P. \& Ellegren, H.
Molec. Ecol. in the press.
6. Primmer, C.R., Møller, A.P. \& Ellegren, H.
Molec. Ecol. 4, 493-498 (1995).
7. Sheldon, F.H. \& Winkler, D.W. Auk 110,
798-824 (1993).
8. Fredholm, M. \& Wintere, A.K. Mamm. Genome
6, 11-18 (1995).
9. Pépin, L. et al. Heredity 74, 53-61 (1995).
10. Schlotterer, C., Amos, B. \& Tautz, D. Nature
354, 63-65 (1991).
11. FitzSimmons, N.N., Moritz, C. \& Moore, S.S.
Molec. Biol. Evol. 12, 432-440 (1995).
12. Sibley, C.G. \& Ahlquist, J.E. Phylogeny and
classification of birds: A study in molecular
evolution (Yale University Press, New Haven,
1990).

1. Rubinsztein et al. Nature Genet. 10, 337-343 (1995)

$627-631(1992)$.

3. Weber, J.L. Genomics 7 524-530 (1990)

(1994).

Ellegren, $\mathrm{H}$

Sheldon, F.H. \& Winkler, D.W. Auk 110 $798-824$ (1993)

. Fredholm, M. \& Wintere, A.K. Mamm Genome Pépin 1 (19t al

0. Schlótterer, C., Amos, B. \& Tautz, D. Nature

classification of birds: A study in molecular 1990).

\title{
Toulouse-Lautrec's diagnosis
}

Sir - The interesting and well documented News \& Views from Julia Frey ${ }^{1}$ comprises an unwarranted allegation and three major errors or misinterpretations that warrant a response.

Regarding the allegation, we simply wish to note that my princeps publication $^{2}$, with Professeur Maurice Lamy, appeared in 1962 and the article on Toulouse-Lautrec's dis-
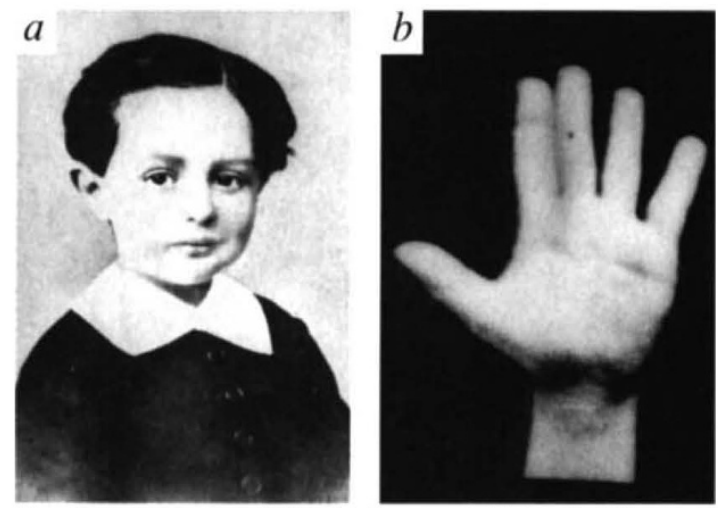

Fig. 1 Photographs of the (a) face and (b) hand of Toulouse Lautrec. ease three years later ${ }^{3}$, at a time where at least the bone disorder specialists were well informed about pycnodysostosis.

The three points that we would like to emphasize about the artist's condition are the facial dysmorphy, the closure of the fontanelle and the hands's deformity.

1) Toulouse-Lautrec definitely had a large forehead, a dysmorphic face with a receding chin and coarse features (Fig. 1). Although less evident, these characteristics are noticeable on the photograph in Frey's article. These features are clearly apparent on many realistic self-caricatures that the painter has left.

2) Regarding the closure of the fontanelle, the evidence is obviously circumstantial. It is based on a statement of Francis Jourdain, a close friend of Toulouse-Lautrec reported to the biographer Henri Perruchot ${ }^{4}$ who, personally, confirmed it to us. Furthermore, the information was taken up again by Sir Terrence
Cawthorne, in his address to the Royal Society of Medicine ${ }^{5}$. We quote: "... and when he was 5 it was noted that his fontanelle has not yet closed".

3) When looking at a document provided by the Bibliothèque Nationale (Fig. $1 b$ ), we wonder how Frey could have found that Toulouse-Lautrec had "large dextrous hands with long tapering fingers". Yvette Guibert, the famous singer who was immortalized by Toulouse-Lautrec's paintings of her, talked of "his comical little hand ... his square hand".

We agree with Frey that it would be possible to confirm the diagnosis and clear up the uncertainties although X-ray of the skull would be a simpler procedure than molecular biology. However, we definitely think that the remains of ToulouseLautrec deserve to rest in peace.

\section{Pierre Maroteaux \\ Hôpital des Enfants Malades \\ 149, Rue de Se'vres}

75743 Paris Cedex 15, France 